\title{
An assessment of plutonium and americium distribution in the lower Rhone Valley environment (France)
}

\author{
C. Duffa and P. Renaud ${ }^{1}$ \\ HEMISPHERES, 2 bis rue Fargès, 13008 Marseille, France \\ 1 IPSN/DPRE/SERNAT/LERCM, CE Cadarache, bâtiment 153, \\ 13108 Saint-Paul-lez-Durance cedex, France
}

\begin{abstract}
As the result of global fallout occurring from 1945 to 1983 , actinides are uniformly present at trace levels in the environment. However, in the lower Rhone valley, higher $\mathrm{Pu}$ and $\mathrm{Am}$ activities are measured, due to a direct or indirect input of radionuclides originated from Marcoule nuclear reprocessing plant releases. Associating measurement and modelling results, a balance of stocks and fluxes of these alpha-emitting actinides in the environment is proposed for the $1950-1998$ period. The ${ }^{238} \mathrm{Pu} /{ }^{299+240} \mathrm{Pu}$ activity ratio is used as a tool to trace and quantify the Marcoule installation's contribution to the total contamination of different environmental compartments. On a global surface of $11000 \mathrm{~km}^{2}$, the soil is the main terrestrial reservoir where $770 \mathrm{GBq}$ of $\mathrm{Pu}$ and Am alpha emitters are stocked. More than $95 \%$ of this soil contamination is due to the global fallout. Since 1950 , the lower Rhone River carried more than $1000 \mathrm{GBq}$ of ${ }^{238} \mathrm{Pu},{ }^{239+240} \mathrm{Pu}$ and ${ }^{241} \mathrm{Am}$ to the Mediterranean Sea, of which 90\% originated from Marcoule liquid release. Therefore, the Rhone River water is considered as another source term for the contamination of the terrestrial environment, because of irrigation practices and accidental floods.
\end{abstract}

\section{INTRODUCTION}

The radionuclides ${ }^{238} \mathrm{Pu},{ }^{239+240} \mathrm{Pu}$ and ${ }^{241} \mathrm{Am}$ are omnipresent in the surface environment due to the fallout from atmospheric nuclear tests (1945-1983) and the disintegration of a US nuclear reactor satellite in $1964[8,11]$. In the lower Rhone valley, since 1958, Marcoule nuclear Centre has to be considered as another source responsible for additional inputs of actinides to the local environment through its atmospheric and liquid release into the Rhone River [2,3,10].

The aim of this study is to assess the Pu and Am fluxes since 1945 and the resulting stocks in the terrestrial environment over a $11000 \mathrm{~km}^{2}$ area mainly situated above Marcoule installations (Figure 1). This way, the relative contributions of each of the two possible origins to the actual actinides distribution in the environment are determined.

Article published by EpP Sciences and avaliable at http./Www.radioprotection.org or http://dx.doi.org/10.1051/radiopro/2002157

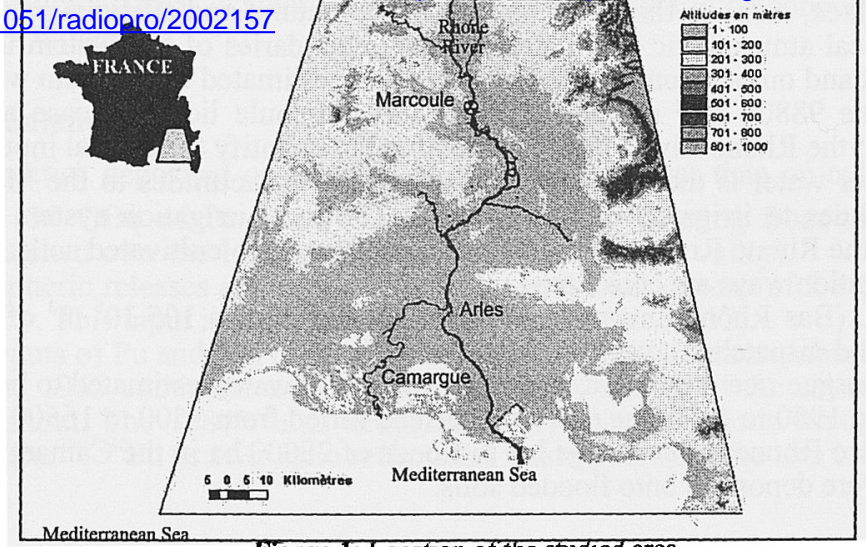

Figure 1: Location of the studied area 


\section{A GLOBAL APPROACH}

The actual distribution of actinides in the lower Rhone valley is the result of many phenomena that occurred at different scales. A global approach, coupling measurement and modelling methods, led to the determination of the flux and stock balance. All the study steps are detailed in [4].

\subsection{Measurements of $\mathrm{Pu}$ and $\mathrm{Am}$ activities}

Measurements were carried out by IPSN, with very low-level alpha spectrometry analysis in environmental samples [5].

\subsubsection{Actinides in soils}

Due to their specific chemical properties, in natural conditions, $\mathrm{Pu}$ and $\mathrm{Am}$ elements are mainly associated to mineral compartments $[6,7,9]$. Their actual spatial distribution in the terrestrial environment can then be estimated examining soil activities.

About 50 cultivated soil samples were collected and measured in the lower Rhone valley in the past 10 years $[2,4,10]$.

\subsubsection{Actinides in plants}

In order to estimate transfers and stocks of $\mathrm{Pu}$ and $\mathrm{Am}$ in plants, about 25 measurements carried out in main cultivated and natural vegetation $[2,4,10]$ were interpreted.

\subsubsection{Origin of the measured contamination}

The ${ }^{238} \mathrm{Pu} /{ }^{239+240} \mathrm{Pu}$ activity ratio is used to trace the origin of the contamination. The actinides originated from global fallout are characterised by a $0.03{ }^{238} \mathrm{Pu} /{ }^{239+240} \mathrm{Pu}$ activity ratio, and Marcoule recent releases' is 0.3 .

Using the mixing balance equation (Equation 1), the contribution of each origin to the total measured contamination can be determined.

$$
\left[\frac{{ }^{238} P u}{{ }^{239+240} P u}\right]_{\text {measure }}=x \cdot\left[\frac{{ }^{238} P u}{{ }^{239+240} P u}\right]_{\text {Marcoule }}+(1-x) \cdot\left[\frac{{ }^{238} P u}{{ }^{239+240} P u}\right]_{\text {fallout }} \text { Equation 1 }
$$

where $\left.x=\frac{\left({ }^{239+240} \mathrm{Pu}\right)_{\text {Marcoule }}}{\left[\left({ }^{239+240} \mathrm{Pu}\right)_{\text {Marcoule }}+\left({ }^{(239+240} \mathrm{Pu}\right)_{\text {falloul }}\right.}\right]$

$\left[{ }^{238} \mathrm{Pu} /{ }^{239+240} \mathrm{Pu}\right]_{\text {measure }}$ is the measured activity ratio,

$\left.{ }^{238} \mathrm{Pu}{ }^{239+240} \mathrm{Pu}\right]_{\text {Marcoule }}$ is the Marcoule release specific activity ratio,

$\left.{ }^{238} \mathrm{Pu}{ }^{239+240} \mathrm{Pu}\right]_{\text {fallout }}$ is the global fallout specific activity ratio,

$\mathrm{X}$ represents the contribution of ${ }^{239+240} \mathrm{Pu}$ originating from Marcoule releases to the total measured activity.

\subsection{Modelling of Pu and Am fluxes}

In the large studied area, actinide fluxes are mainly due to natural and artificial particulate removal. The knowledge of the local atmospheric and hydrographical boundaries of the system is necessary to model mass transfers. Input and output from the Rhone River were estimated as the main way of transfer (Figure 2). Erosion from the $98800 \mathrm{~km}^{2}$ catchment basin and Marcoule liquid release are source terms that supply $\mathrm{Pu}$ and $\mathrm{Am}$ to the Rhone River. Both are modelled to quantify the annual input.

The Rhone River water is then a transfer compartment for actinides to the Mediterranean Sea and distributes radionuclides to irrigated or flooded soils. The local irrigation system is complex as many canals, supplied by the Rhone River, are used to distribute water to cultivated soils. For the period 19501998, two main irrigation ways are considered :

The BRL (Bas Rhône Languedoc) canal annually pumps $105.10^{6} \mathrm{~m}^{3}$ of water from the river course, and dispatches it onto cultivated soils;

- The Camargue rice growing uses a large volume of water, estimated to be $28000 \mathrm{~m}^{3}$.ha $\mathrm{a}^{-1}$. Over the period 1960 to 1998 , the rice field surface varied from 3500 to 16500 ha.

In 1993 and 1994, two Rhone River risings led to floods of 20000 ha in the Camargue delta. 391000 tons of river sediments were deposited onto flooded soils. 


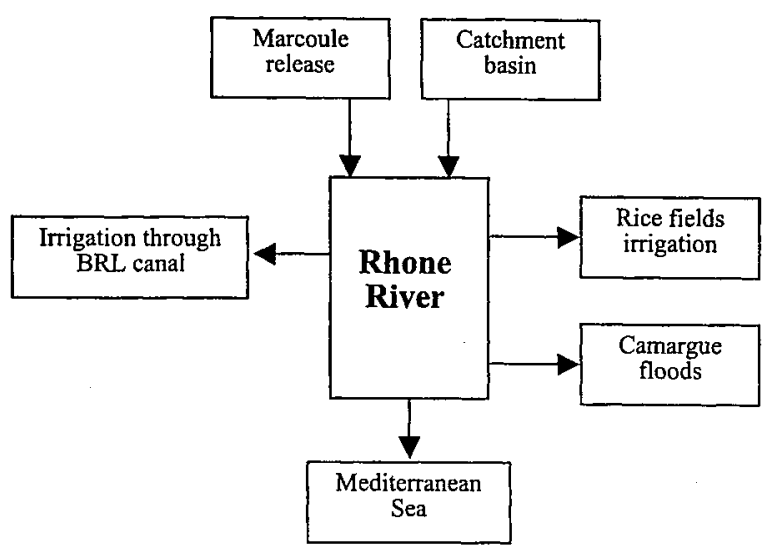

Figure 2 : Actinide fluxes in the lower Rhone hydrological system

As plant mass activities and local cultural productions are known, actinide exports due to harvesting are also modelled as an annual flux. This calculation can be done for harvests post-fallout (after 1983), as direct deposit onto plants is not considered.

\section{RESULTS}

\subsection{Estimated compartmental activities}

Mean soil and terrestrial plant actual activities due to global fallout are deduced from measurements results (Table 1).

Table 1: Mean mass activities due to global fallout and associated uncertainties $\left(\times 10^{-3} \mathrm{~Bq} \cdot \mathrm{kg}^{-1} \mathrm{sec}\right)$

\begin{tabular}{c|ccc}
\hline & ${ }^{238} \mathbf{P u}$ & ${ }^{2397240} \mathrm{Pu}$ & ${ }^{241} \mathrm{Am}$ \\
Cultivated soils & $3.3 \pm 0.4$ & $111.6 \pm 8.2$ & $46 \pm 3$ \\
Fruits & $0.015 \pm 0.007$ & $0.5 \pm 0.2$ & $3.4 \pm 1.5$ \\
Leafy vegetables & $0.07 \pm 0.02$ & $2.3 \pm 0.6$ & $3.7 \pm 0.8$ \\
Fruit vegetables & $0.018 \pm 0.006$ & $0.6 \pm 0.2$ & $0.6 \pm 0.2$ \\
Rice & $0.007 \pm 0.003$ & $0.17 \pm 0.07$ & $0.11 \pm 0.08$ \\
Cereals & $0.004 \pm 0.001$ & $0.13 \pm 0.05$ & $0.09 \pm 0.05$ \\
Forage & $0.03 \pm 0.01$ & $1.0 \pm 0.3$ & $0.6 \pm 0.2$ \\
\hline
\end{tabular}

Locally, some samples exhibit actinide enrichment due to Marcoule release. This enrichment is measurable in two particular areas, Camargue and Marcoule installation neighbourhood, where total $\mathrm{Pu}$ activity is 2 to 5 times higher.

\subsection{Flux and stock balance}

Considering that activities deposited on wooded soils are $30 \%$ greater than on cultivated ones [1], we estimate that $770 \pm 54 \mathrm{GBq}$ of $\mathrm{Pu}$ and $\mathrm{Am}$ alpha emitters originating from the global fallout are tomogeneously dispatched over the $11000 \mathrm{~km}^{2}$ area in the lower Rhone valley.

Marcoule atmospheric releases are responsible for an additional deposit of $2.8 \mathrm{GBq}$ within a $30 \mathrm{~km}^{2}$ area around the facility. This input is attributed to old military activities [12].

The modelled inputs of $\mathrm{Pu}$ and $\mathrm{Am}$ to the river are used to calculate mean annual volume activities in water (Figure 3). The 1965 maximum activity corresponds to erosion of the catchment basin after the main nuclear tests fallout. The 1980's high actinides contents in the Rhone River is due to Marcoule liquid release. The ${ }^{238} \mathrm{Pu} /{ }^{39+240} \mathrm{Pu}$ activity ratio reflects the mixing between the two origins. 


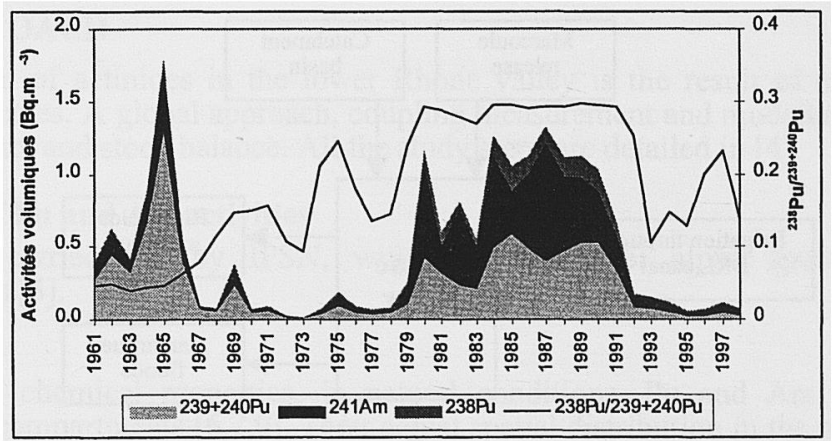

Figure 3: Annual mean ${ }^{238} \mathrm{Pu},{ }^{239+240} \mathrm{Pu}$ et ${ }^{241} \mathrm{Am}$ volume activities (Bq. ${ }^{-3}$ ), and corresponding ${ }^{238} \mathrm{Pu} /{ }^{239+240} \mathrm{Pu}$ activity ratio in the Rhone River down to Marcoule Nuclear Plant

From these results, activities transferred from the river to soils can be calculated :

Some $0.6 \mathrm{GBq}$ to cultivated soils via the BRL canal since 1960 ;

- $\quad 5.5 \mathrm{GBq}$ to rice fields in the Camargue, through irrigation practice, but draining would take 2 GBq off these soils;

0,2 GBq of Pu and Am through the 1993/1994 Camargue.

Total activity stocked in the terrestrial environment is then evaluated to $805 \mathrm{GBq}$. Activities transferred to vegetation represent less than $0.1 \%$ of the soil total stock. Figure 4 summarises estimated fluxes and stocks.

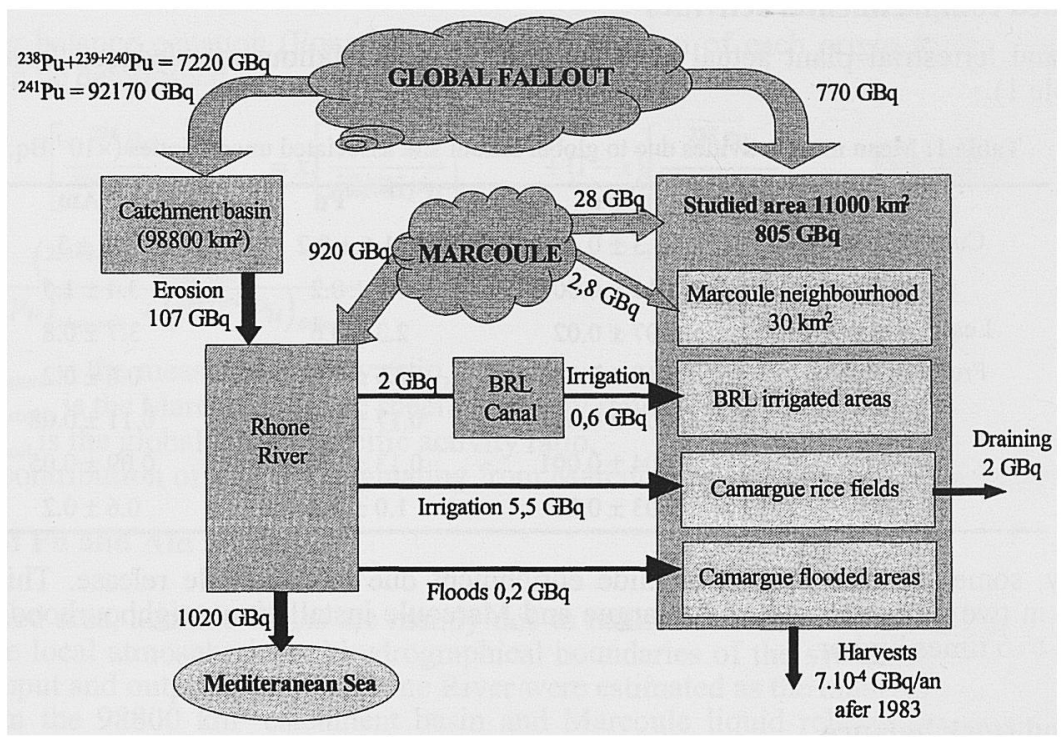

Figure $4:{ }^{238} \mathrm{Pu}+{ }^{239+240} \mathrm{Pu}+{ }^{241} \mathrm{Am}$ integrated fluxes for the period $1945-1998$

\section{CONCLUSION}

The actual distribution of $\mathrm{Pu}$ and $\mathrm{Am}$ in the environment is the result of input of low quantities of these radionuclides since 1945. Global fallout is responsible for uniform contamination of the lower Rhone valley soils, whereas Marcoule releases led to localised contamination. The activity ratio is a good tool to determine the origin of the measured contamination, and was greatly used in this study.

Although the environmental fate of $\mathrm{Pu}$ and $\mathrm{Am}$ has ever been examined in several projects, the study of their distribution in a large area and period of time, in a multi-compartmental scale is of actual concern. We show that, in the terrestrial environment, the soil is now the major actinide reservoir, and even though this French region is an agricultural one, annual crops led to very low activity transfers. Actinides are then naturally trapped in this compartment for a long time unless anthropic perturbations modify it. 
On another hand, Marcoule discharge is responsible for $90 \%$ of the cumulated input in the Rhone River, and is consequently the major contributor for $1020 \mathrm{GBq}{ }^{238,239,240} \mathrm{Pu}$ and ${ }^{241} \mathrm{Am}$ exported in the Mediterranean Sea for the past 50 years.

\section{References}

[1] Bunzl K., Kracke W., 1988, Cumulative deposition of ${ }^{137} \mathrm{Cs},{ }^{238} \mathrm{Pu},{ }^{239+240} \mathrm{Pu}$ and ${ }^{241} \mathrm{Am}$ from global fallout in soils from forest, grassland and arable land in Bavaria (FRG), Journal of Environmental Radioactivity $8: \mathrm{p} 1-14$.

[2] Descamps B., 1997, Etude radioécologique de l'environnement terrestre du site de Marcoule Année 1995-, Rapport IPSN/DPRE/SERE 97/002.

[3] Duffa C., Renaud Ph, Calmet D., 2001, Activités de ${ }^{238} \mathrm{Pu}$ et ${ }^{239+240} \mathrm{Pu}$ dans les sols cultivés de la basse vallée du Rhône, Comptes-rendus de l'Académie des Sciences, Sciences de la Terre et des Planètes 4, Fascicule a.

[4] Duffa C., 2001, Répartition du plutonium et de l'américium dans l'environnement terrestre de la basse vallée du Rhône, Doctorat de l'Université Aix-Marseille III.

[5] Goutelard F., Morello M., Calmet D., 1998, Alpha spectrometry measurement of Am and Cm at trace level in environmental samples using extraction chromatography, Journal of Alloys and Compounds 271-273 : p 25-30.

[6] Hakonson T. E., Watters R. L., Hanson W. C., 1981, The transport of plutonium in terrestrial ecosystems, Health Physics $40:$ p 63-69.

[7] Hanson W. C., 1975, Ecological considerations of the behaviour of plutonium in the environment, Health Physics 28 : p 529-537.

[8] Harley J. H., 1980, Plutonium in the environment - A review, Journal of Radiation Research 21 : p,83-104.

[9] Little C. A., Whicker F. W., Winsor T. F., 1980, Plutonium in grassland ecosystem at Rocky Flats, Journal of Environmental Quality $9:$ p 350-354.

[10] Lumia G., Descamps B., 1995, Etude radioécologique de 1'environnement terrestre du site de Marcoule -Année 1993-, IPSN/DPEI/SERE 95/028.

[11] Perkins R. W., Thomas C. W., 1980, Worldwide Fallout. Pages 53-82 in W. C. Hanson editor. "Transuranic elements in the environment", U.S. DOE, USA.

[12] Renaud P., Duffa C., Descamps B., Louvat D., 2000, Répartition de ${ }^{238} \mathrm{Pu},{ }^{239,240} \mathrm{Pu}$ et ${ }^{241} \mathrm{Am}$ dans l'environnement de l'installation du Centre de Marcoule. Rapport IPSN/DPRE/SERNAT/2000-02. 